\title{
Commentary
}

\section{Doctors' Extended Shifts as Risk to Practitioner and Patient: South Africa as a Case Study}

\author{
Koot Kotze ${ }^{1, *} \mathbb{C}$, Helene-Mari van der Westhuizen ${ }^{1} \mathbb{(}$, Eldi van Loggerenberg ${ }^{2}$, Farah Jawitz ${ }^{3} \mathbb{C}$ \\ and Rodney Ehrlich ${ }^{4}$ (D) \\ 1 Nuffield Department of Primary Care Health Sciences, Radcliffe Primary Care Building, \\ University of Oxford, Oxford OX2 6GG, UK; helene.vanderwesthuizen@phc.ox.ac.uk \\ 2 Helen Joseph Hospital, Rossmore, Johannesburg 2092, South Africa; eldivanloggerenberg@gmail.com \\ 3 Saïd Business School, University of Oxford, Oxford OX1 1HP, UK; farahjawitz@gmail.com \\ 4 Division of Occupational Medicine, School of Public Health and Family Medicine, University of Cape Town, \\ Observatory, Cape Town 8001, South Africa; rodney.ehrlich@uct.ac.za \\ * Correspondence: koot.kotze@phc.ox.ac.uk
}

Received: 3 July 2020; Accepted: 6 August 2020; Published: 12 August 2020

check for updates

\begin{abstract}
Extended shifts are common in medical practice. This is when doctors are required to work continuously for more than $16 \mathrm{~h}$, with little or no rest, often without a maximum limit. These shifts have been a part of medical practice for more than a century. Research on the impact of fatigue presents compelling evidence that extended shifts increase the risk of harm to patients and practitioners. However, where the number of doctors is limited and their workloads are not easily reduced, there are numerous barriers to reform. Some of these include a perceived lack of safer alternatives, concerns about continuity of care, trainee education, and doctors' preferences. As such, working hour reorganisation has been contentious globally. South Africa, a middle-income country where extended shifts are unregulated for most doctors, offers a useful case study of reform efforts. The South African Safe Working Hours campaign has promoted working hour reorganization through multi-level advocacy efforts, although extended shifts remain common. We propose that extended shifts should be regarded as an occupational hazard under health and safety legislation. We suggest options for managing the risks of extended shifts by adapting the hierarchy of controls for occupational hazards. Despite the challenges reform pose, the practice of unregulated extended shifts should not continue.
\end{abstract}

Keywords: shift work; extended shifts; on-call; working hour organization; duty hours; fatigue; occupational hazards; sleep deprivation

\section{Introduction}

Sleep deprivation, long accepted as an inseparable part of medical practice globally, is increasingly being recognized as a risk factor for patient and practitioner harm [1-3]. Rather than a weakness, the human need for regular sleep should be seen as a physiological reality. This poses a problem in healthcare, where qualified staff must be available at all hours of the day.

This article focuses on the after-hours work of doctors (although it could be applied to any health worker working extended shifts), which can be referred to as being "on-call" [4], extended duration work shifts [5], extended shifts [2], or continuous duty [6]. Whereas some disciplines allow doctors to work remotely on standby, this article focuses on the work of doctors who are required to be on-site for an extended period. We will use the term extended shifts throughout this article, defined as working more than 16 h continuously. 
We recognize that there is variation in the opportunity for rest during an extended shift, depending on the discipline, workload, and seniority. In many countries there is a dearth of regulations pertaining to the maximum duration of an extended shift and it should be of concern that doctors have been found to work continuously with little or no rest for up to $76 \mathrm{~h}$ [7] (p. 9). While other work features that contribute to fatigue include frequency of shifts, total number of hours worked, and intensity and complexity of tasks, we limit our discussion to extended shifts.

We suggest that extended shifts and the resulting fatigue are an occupational risk factor (by increasing the risk of other workplace injuries) and an occupational hazard in themselves. We argue that specific regulation is required to mitigate this hazard whilst balancing the safety of practitioners and patients. In some countries this is enabled by existing occupational health laws. When applied to the risk posed by fatigue in medical settings, these laws oblige employers to take steps to mitigate this risk. We will present a case study from South Africa, illustrating efforts undertaken to achieve such risk mitigation regarding doctors' working hours. Through the case study we will explore the contextual factors which may have bearing on such attempts.

\section{Origins of Extended Shifts in Medical Practice}

The on-call system utilized by medical doctors globally has been part of hospital-based healthcare for over a century. Although it is likely that this system has developed differently in many regions of the world, the USA is an influential example. In the late 19th century, pioneering surgeon, William Halsted, introduced multiple innovations in surgical procedures, including the use of gloves during surgery, and rigorous training for prospective surgeons [8]. He expanded the apprenticeship for surgeons through a period of "residency" - which involved staying on the hospital site and being available for emergencies, at all hours of the day and every day of the year [9]. This "restricted lifestyle" also meant residents received little or no pay, and were discouraged from marriage [9]. Halsted introduced the use of cocaine for topical anaesthesia, but also sustained his own "excellent physical vigour" by abusing this stimulant drug $[8,10]$.

\section{The Impact of Extended Shifts on Safety}

A great deal has been learned about workplace and patient safety since Halsted's residency programme was instituted. A 2011 systematic review that included studies of health care and non-medical industries concluded that both shift work and long working hours had a 'substantial and well-documented detrimental effect on safety' [11]. The review reports increased accident rates, with the findings most relevant to safety-critical activities such as transport and health sectors. It also found that work periods exceeding $8 \mathrm{~h}$ carry an accumulating risk of accidents such that the risk of accidents at around $12 \mathrm{~h}$ is twice the risk at $8 \mathrm{~h}$. Extended shifts are strictly regulated in aviation, road freight, and passenger-carrying vehicle industries, yet in many countries the medical industry lags behind [12] (p. 2).

The death of Libby Zion in New York in 1984 as a result of a fatigue-related error made by a junior doctor is often cited as a turning point in working hour organisation and patient safety in the USA. An enquiry into contributing factors to her death led to limitation of the maximum duration of an extended shift in the US for residents to $24 \mathrm{~h}[9,13]$.

Extended shifts may lead to patient harm through medical errors [2]. In a prospective, randomized study of junior doctors in the United States, those working extended shifts ( $>24 \mathrm{~h}$ ) compared to shorter shifts $(<16 \mathrm{~h})$ made substantially more serious medication errors $(20.8 \%)$, and 5.6 times as many serious diagnostic errors [14]. Fatigue may also affect empathy and patient interaction negatively [15] (p. 11).

There is risk of acute harm to practitioners. A systematic review demonstrated an elevated risk for road traffic incidents in doctors after extended shift work [16]. The largest study included in the review followed 2500 junior doctors in the USA over a year and found that those working an extended duration shift $(>24 \mathrm{~h}$ ) were 2.3 times more likely to have a motor vehicle car crash, and 5.9 times more likely to have a near miss, than following a non-extended duration shift [17]. A prospective cohort 
study of 2737 intern doctors in the USA showed percutaneous injuries were more frequent during extended shifts than non-extended shifts [18].

\section{Regulating Extended Shifts}

There are global examples of profession-wide regulations aimed at patient and practitioner safety. The European Working Time Directive places limits on both continuous and total hours worked [3] (p. 86). It stipulates a minimum rest period per day of $11 \mathrm{~h}$, effectively limiting the maximum duration of an extended shift to $13 \mathrm{~h}$. In Australia, there is a National Code of Practice-Hours of Work, Shiftwork and Rostering for Hospital Doctors-released in 1999. The Australian Medical Association utilizes a Risk Assessment Guide and a Risk Assessment Checklist instead of absolute limits on working hours to help assess the risk level of an individual's working hours [7].

In the United States in 2011 the Accreditation Council for Graduate Medical Education (ACGME) introduced a 16-h limit for extended duration shifts for first-year residents. A randomized control trial comparing standard $16 \mathrm{~h}$ shifts with shifts exceeding $16 \mathrm{~h}$, found noninferior patient outcomes and no significant difference in residents' satisfaction with overall well-being and education quality [19]. This study was used as justification in rolling back maximum working hour limits under ACGME regulations, despite the authors' conclusion being contested [20].

\section{Barriers to Change}

Each of the above instances of regulation and reform has met, or continues to receive, considerable resistance and we discuss some of the salient objections to limiting extended shifts.

\subsection{Shortage of Doctors}

There is a global shortage of health workers (including doctors) which is not projected to be resolved in the near future without extensive intervention [21] (p. 44). Using this objection in favour of extended shifts presumes regulation must inevitably entail shortening overall number of hours (which has been the case in Europe and the US). We contest this as well as the assumption that extended shifts make the best use of the existing scarce pool of doctors. To the contrary, extended shifts may push practitioners from the profession or towards working in certain specialities where extended shifts are less common [22]. As outlined below, risk mitigation does not necessarily have to rely on having more doctors or reduced overall hours.

\subsection{The Hazards of Shift Work}

There are numerous ways to reduce fatigue whilst still providing after hours care. These include limiting consecutive hours worked by doctors by instituting non-extended shifts (lasting less than $16 \mathrm{~h}$, hereafter "shift work") and measures such as pre-call rest periods, floating shifts, and overlapping shifts [23].

Shift work can refer to a variety of shift lengths [3] (p. 74) or to work outside of the hours of 09h00-17h00 [24]. Nurses, for example, commonly work $12 \mathrm{~h}$ shifts [25]. Shift work is associated with an increased risk of accidents, especially on the night shift and increasingly as the shift exceeds $8 \mathrm{~h} \mathrm{[26].} \mathrm{Furthermore,} \mathrm{shift} \mathrm{work} \mathrm{is} \mathrm{associated} \mathrm{with} \mathrm{well-studied} \mathrm{health} \mathrm{hazards} \mathrm{including} \mathrm{increased}$ risk of cancer [27], cardiovascular disease [28], and metabolic disorders [29]. It is not clear weather the harmful sequelae of shift work result from circadian disruption, disturbed sleep, associated behaviours, psychological stress, or an interaction between these and other proposed mechanisms [29]. At least some of the harm demonstrates a dose-response relationship with night shift work. Therefore a move to working shifts would not eliminate practitioner harm. However, it is likely that extended shifts include many of the risks of shorter shift work whilst further increasing the risks of errors or accidents as the duration of the shift increases.

Shorter shifts necessarily mean that doctors hand over patient care more frequently to the incoming team. There is some concern that this increases the risk of error and detracts from continuity of care. 
It is worth noting that a systematic review on this topic did not find reduced quality of care with shifts less than $16 \mathrm{~h}$ [30]. If patient care is the chief priority it is counterintuitive to present extended shifts as a solution, as these have been associated with increased treatment and diagnostic error [14].

\subsection{Concerns about Education}

Opinions differ on the impact of limiting extended shifts on medical education. Some fear this would reduce the overall quality of medical education due to lack of clinical exposure. A 2010 review found that a maximum shift duration of $16 \mathrm{~h}$ had no adverse effect or possibly a positive effect on the educational outcomes of medical residents [30].

Both acute and chronic sleep deprivation are known to impair memory among doctors [3] (p. 85). Although shorter shifts would not necessarily reduce chronic sleep deprivation, it is difficult to argue that extended shifts contribute to more learning, when much of the time worked is spent in a state of profound fatigue.

There are also concerns that shortened shifts will prevent acclimatisation to fatigue. However, repeated extended shifts have not been shown to decrease the negative impact of fatigue through acclimatisation $[1,6,31]$.

\subsection{Doctors' Preference}

Doctors may prefer to work extended shifts or that their subordinates do so, as this allows for more uninterrupted time off [3] (p. 74). In any other safety critical discipline, such as aviation, preference for a dangerous arrangement would not be considered when developing regulations. Promoting greater awareness among doctors about the risks of extended shifts to patients and themselves could play an important role, although this would not obviate the need for regulation.

\section{Case Study: The Safe Working Hours Campaign in South Africa}

In South Africa, medical doctors provide after-hours care by working $24 \mathrm{~h}$ shifts where they are "on-call" on site, followed by a day of "post-call" work [4] (p. 62). Although rest may be possible, there is usually no regulation to prevent a doctor from working continuously throughout this period,

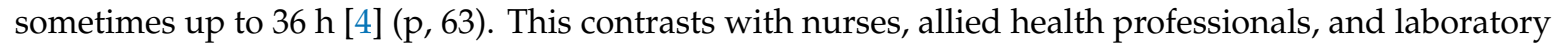
workers, who are part of the $24 \mathrm{~h}$ provision of healthcare but provide this care in 8 or $12 \mathrm{~h}$ shifts [4] (p. 52)

During their two-year internship after completing medical school, South African junior doctors receive placements in training facilities across the country, rendering after hours services in speciality departments such as surgery, obstetrics and gynaecology, and internal medicine. They receive varying degrees of support, from on-site supervision to telephone-based consultations with seniors and perform procedures that include caesarean sections and trauma care.

Doctors' legal rights to demand working hour protections offered by the Basic Conditions of Employment Act of 1997 are curtailed by their earning more than the specified threshold of R205 433.30 (approximately €9 800) per annum [32]. The right to "demand" is replaced by the right to "negotiate" specific overtime arrangements with employers. However, threshold exemptions do not absolve the employer of the need to comply with occupational health laws [33].

Prior to 2017, the Health Professions' Council of South Africa (HPCSA), the regulatory body for medical professionals, had set a 30-h limit on extended shifts for medical graduates during their two years of internship [34]. Beyond these first two years of work as a doctor, no maximum duration has been set.

The Safe Working Hours (SWH) campaign was started in 2014 by medical students and junior doctors, including four of the authors (K.K., H.v.d.W., E.v.L. and F.J.). The narrative account of this case study is informed by their experiences and publicly available information. The aim of the campaign was to generate an evidence-based discussion around working hour regulations in South Africa and advocate for revised regulations. An online petition asking for an urgent revision of doctors' working 
hour regulations gathered over 7000 digital signatures. SWH questioned the 30-h limit for intern doctors proposed by the HPCSA, calling for shift duration to be limited to $16 \mathrm{~h}$. SWH volunteers consulted with various stakeholders to advocate for the introduction of maximum shift durations for medical doctors. These included the South African Medical Association (SAMA), the HPCSA, Western Cape Department of Health, National Department of Health and SWH representatives at hospitals throughout the country.

The junior doctor interest group of SAMA, Judasa, led a colour coded armband campaign to raise awareness among practitioners and patients of the harms of extended shifts. Doctors wore green armbands for the first $24 \mathrm{~h}$ of their shift, then switched to an orange armband, and from $30 \mathrm{~h}$ used a red armband. This campaign did not have sustained uptake. The reasons for this may include that it competed with other clinical priorities, did not directly engage those with the authority to change working conditions, or that some doctors felt their practice became unsafe during the 'green' period, i.e., before $24 \mathrm{~h}$.

In 2016 the campaign received renewed attention after a junior doctor died in a motor vehicle accident while driving home after a 24-h extended shift. SWH created the 'Share your story' campaign, where doctors could share their experiences of extended shifts. These included adverse effects on patient care, multiple reports of motor vehicle accidents while driving home after extended shifts, and the psychological impact of working while sleep impaired. A video compilation of the 'Share your story' campaign reached approximately 17,000 viewers on social media. A reuploaded version is available online [35] (see Figure 1). The SWH campaign was featured in 23 national newspaper articles, 17 radio interviews and two opinion pieces by campaign volunteers for national newspapers and on national television. Township ER [36], a documentary that follows five South African junior doctors on an extended shift, was screened at various health facilities and medical schools to facilitate discussion.

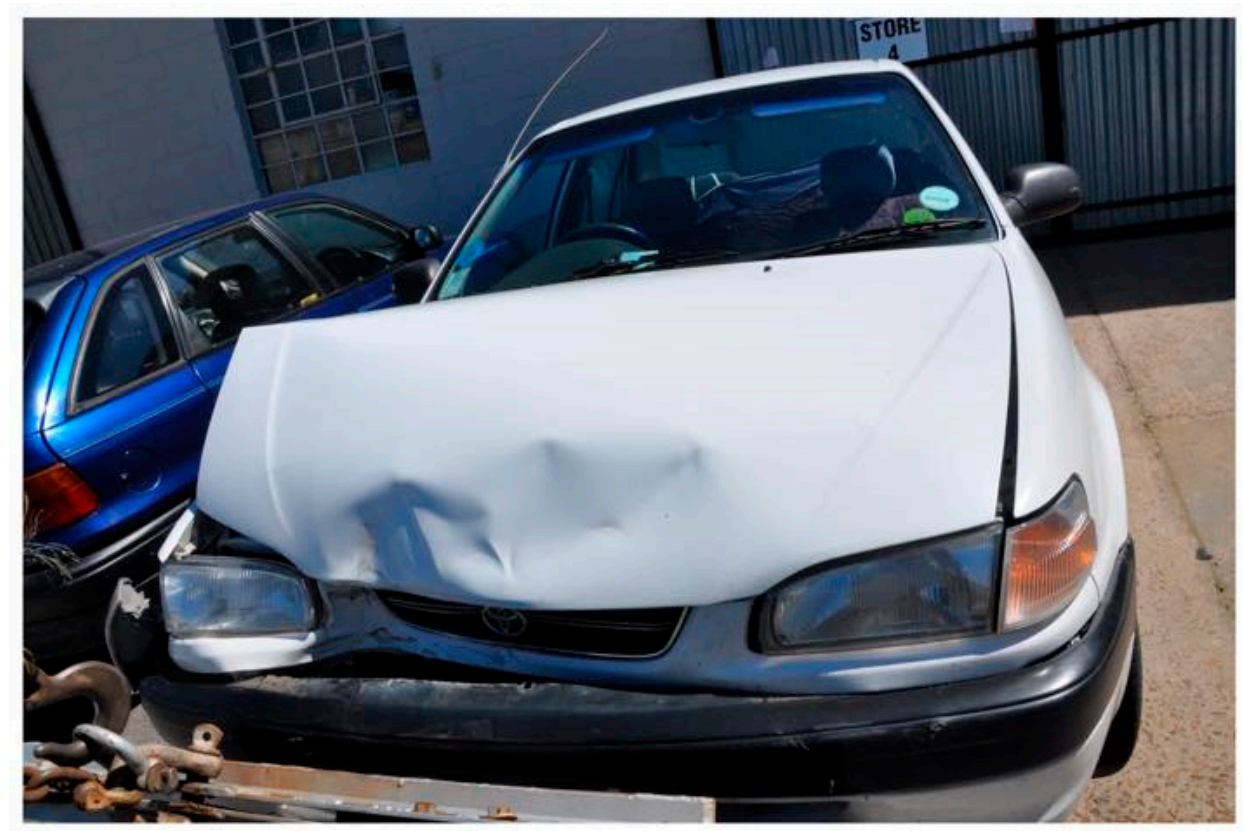

Figure 1. A photo of a motor vehicle crash submitted by a junior doctor as part of the 'Share your Story' campaign. The intern doctor worked a $26-\mathrm{h}$ extended shift and was required to drive to a clinic to work an additional $5 \mathrm{~h}$, when they were involved in a collision. Reproduced with permission from the photographer.

In 2016, two years after the SWH campaign started, the HPCSA circulated a document outlining changes to internship training regulation, shortening maximum allowable shift duration from $30 \mathrm{~h}$ to $24 \mathrm{~h}$ with a two-hour period for patient hand-over. This was included in a 2017 guideline on internship training [37]. It is not yet clear whether the $24 \mathrm{~h}$ regulation has been implemented throughout South 
Africa, although an advocacy report published on the SWH website suggests that extended shifts are still practiced widely [38].

The HPCSA's maximum shift duration for interns demonstrates an important acknowledgement of the potential for harm to patient and practitioners. However, it is doubtful whether a $24 \mathrm{~h} \mathrm{limit}$ is sufficient to mitigate risk of harm. The shift limit contrasts sharply with the unregulated shifts which doctors can be expected to work beyond internship.

The National Department of Health also formed a Safe Working Hours task team in 2016, but this does not appear to be active. The campaign was successful in engaging with the public about the importance of working hour regulations and amplifying the voices of junior doctors who bear the brunt of extended shifts. Some senior doctors voiced opposition to the campaign, deeming extended shifts a rite of passage and expressing reluctance to be involved in additional handover rounds associated with shorter shifts.

An alternative route would be to use existing occupational health legislation in South Africa. Given the risks of extended shifts described above, it can be argued that this practice contravenes the country's Occupational Health and Safety Act of 1993. This law states that it is the employer's responsibility to provide a safe working environment and to take steps to mitigate risks to both employees and others "directly affected" [39]. Medical employers would have to demonstrate that they have undertaken the risk assessment required by the Act

We believe that given the probability that extended shifts may result in harm (summarised above), employers would have to take steps to mitigate this risk (See Table 1). The South African National Health Act of 2003 also obligates the employer to minimise injury to health care personnel and this poses another avenue to hold employers accountable [40]. To our knowledge, these interpretations have not yet been tested in South African courts with regards to extended shifts.

\section{Extended Shifts as an Occupational Hazard}

In taking steps to mitigate the hazard of extended shifts, it is useful to apply the hierarchy of controls, such as the one described by the US National Institute of Occupational Safety and Health [41] (See Figure 2). Usually used for physical, dust, and chemical hazards, the hierarchy arranges solutions in order of theoretical effectiveness based on the degree of control of the hazard. Table 1 demonstrates how this hierarchy may be adapted to extended shifts. Conceiving of extended shifts in this manner has the purpose of categorising appropriate and feasible steps to address the hazard in a stepwise manner within an occupational health framework.

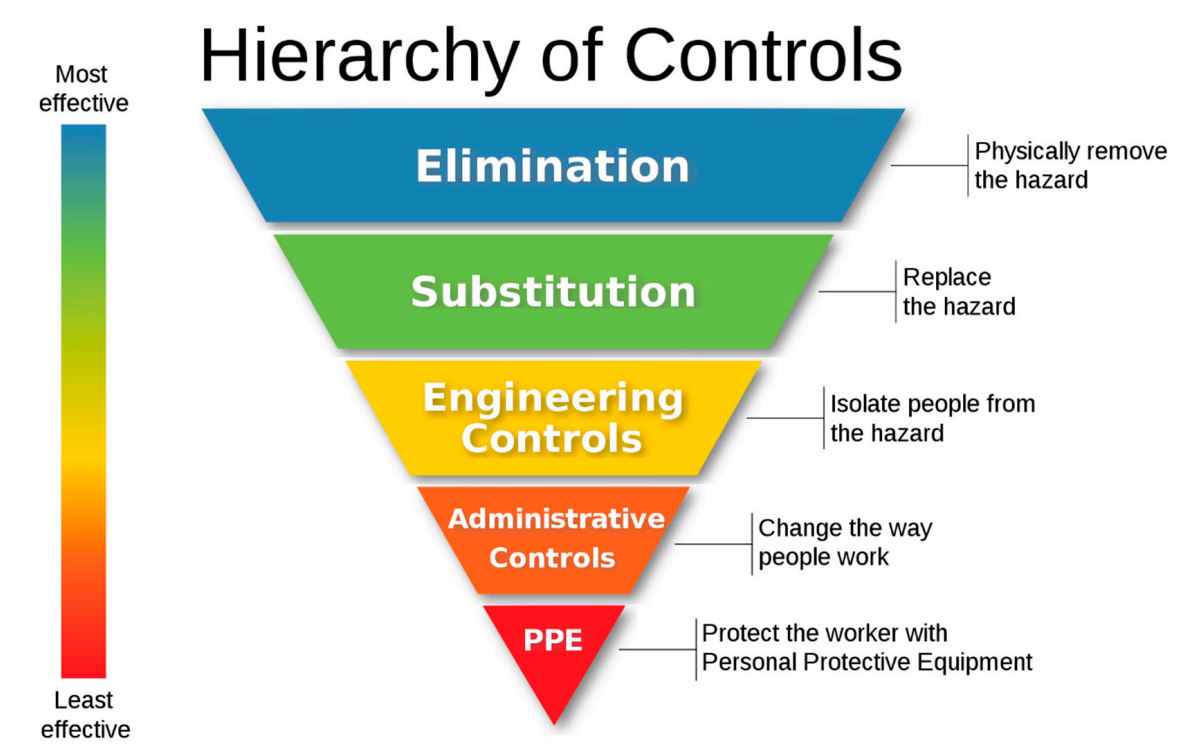

Figure 2. The hierarchy of controls for occupational hazards. Copyright: public domain [42]. 
Table 1. Adapting the hierarchy of controls to extended shifts.

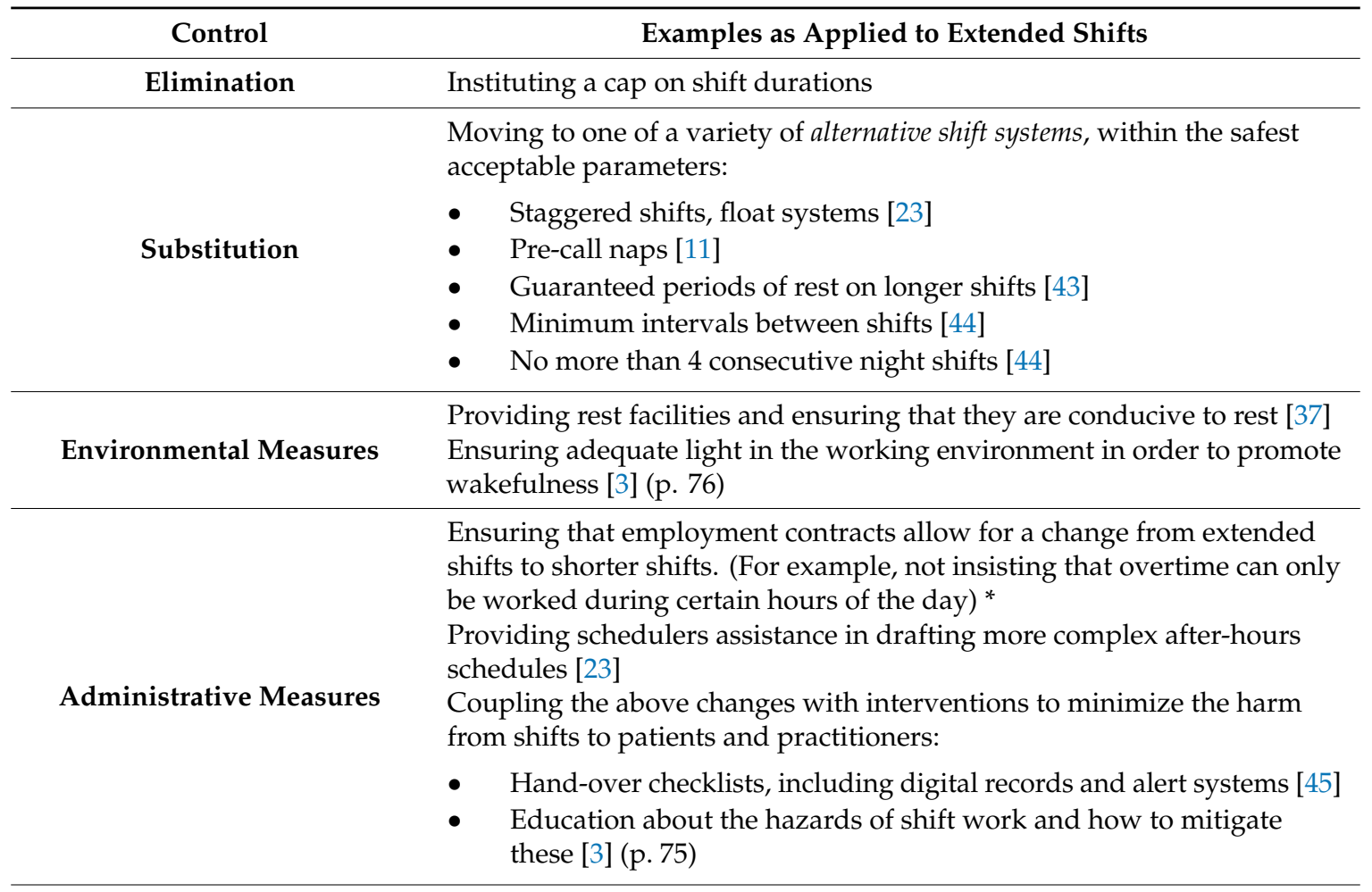

Preventing the increased risk posed to patients by those on extended shifts by:

- "Buddy systems", where a rested person checks the work of the post-call person *

Personal Protective Measures

- $\quad$ System of additional checks for high risk work [46]

- $\quad$ Signalling which doctors are most fatigued through colour coded armbands [47]

Preventing death or injury of the practitioner:

- Delegating dangerous procedures*

- $\quad$ Encouraging the use of public transport [46]

* Suggested examples obtained from practitioners and managers during the Safe Working Hours campaign in South Africa.

The measures listed are not exhaustive and consist of suggested examples obtained from published literature and regional guidelines, where cited, as well as from practitioners and managers during the Safe Working Hours campaign in South Africa (marked with *). Research as well as trial-and-error implementation are needed to determine the effectiveness of the various measures. We have also attempted to reflect the role of individual doctor agency by placement lower down within the hierarchy.

\section{Conclusions}

The medical profession has become inured to the risks associated with the historic practice of extended shifts, and has not modified this practice to reflect emerging evidence. Conceiving of extended shifts as an occupational hazard brings this danger into focus and into the domain of occupational health. It also directs attention to a menu of options to mitigate potential for harm. This approach should make risk reduction possible despite a shortage of doctors, and without necessarily reducing total hours worked. This assessment can then be balanced against considerations such as continuity of care and safe handover. Working at night or in shifts will always entail some increased health risk. However, leaving extended shifts unregulated in any country should be regarded as unacceptable. 
The South African case study shows that in addressing the problem of extended shifts in any jurisdiction, context matters. It illustrates how different advocacy strategies have been used for specific regulatory reform, with limited success. The case study also shows how existing labour and occupational health legislation could be applied to the hazard of extended shifts. Medical practitioners must recognise that extended shifts are not an immovable or intrinsic part of healthcare practice, but an occupational hazard which must be addressed.

Author Contributions: Conceptualization, K.K. and H.-M.v.d.W.; writing—original draft, K.K.; writing—review and editing, K.K., H.-M.v.d.W., E.v.L., F.J., R.E. All authors have read and agreed to the published version of the manuscript.

Funding: This research received no external funding.

Acknowledgments: K.K., H.-M.v.d.W., E.v.L. and F.J. would like to acknowledge the volunteers and stakeholders whose efforts comprise the SWH campaign in South Africa, which has provided such a valuable case study.

Conflicts of Interest: K.K., H.-M.v.d.W., E.v.L. and F.J. participated in the SWH campaign in South Africa in a voluntary capacity and received no funding for this work. No further conflict of interest to declare.

\section{References}

1. Walker, M.P. A sleep prescription for medicine. Lancet 2018, 391, 2598-2599. [CrossRef]

2. Lockley, S.W.; Landrigan, C.P.; Barger, L.K.; Czeisler, C.A. When policy meets physiology: The challenge of reducing resident work hours. Clin. Orthop. Relat. Res. 2006, 449, 116-127. [CrossRef]

3. Surani, S.; Subramanian, S. Sleep \& Safety, 1st ed.; Bentham Science Publishers: Sharjah, UAE, 2011.

4. Kisting, S.; Dalvie, A.; Lewis, P. South Africa: Case Study on Working Time Organization and Its Effects in the Health Services Sector; ILO: Geneva, Switzerland, 2016; Available online: www.ilo.org/publns (accessed on 22 July 2020).

5. Weaver, M.D.; Landrigan, C.P.; Sullivan, J.P.; O’Brien, C.S.; Qadri, S.; Viyaran, N.; Wang, W.; Vetter, C.; Vetter, C.A.; Barger, L.K. The Association Between Resident Physician Work-Hour Regulations and Physician Safety and Health. Am. J. Med. 2020, 133, e343-e354. [CrossRef]

6. Philibert, I. Sleep loss and performance in residents and nonphysicians: A meta-analytic examination. Sleep 2005, 28, 1392-1402. Available online: http://www.ncbi.nlm.nih.gov/pubmed/16335329 (accessed on 22 July 2020).

7. Australian Medical Association. Managing the Risks of Fatigue in the Medical Workforce 2016. Available online: https://web.archive.org/web/20200810152216/https://ama.com.au/sites/default/files/docum ents/150717\%20-\%20AMA\%20Safe\%20Hours\%20Audit\%202016.pdf (accessed on 10 August 2020).

8. Spirling, L.I.; Daniels, I.R. William Stewart Halsted-Surgeon extraordinaire: A story of ‘drugs, gloves and romance'. J. R. Soc. Promot. Health 2002, 122, 122-124. [CrossRef]

9. Wallack, M.; Chao, L. Resident work hours. J. Neurosurg 2012, 116, 475-476. [CrossRef]

10. Cameron, J.L. William Stewart Halsted: Our surgical heritage. Ann. Surg 1997, 225, 445-458. [CrossRef]

11. Wagstaff, A.S.; Lie, J.A.S. Shift and night work and long working hours-A systematic review of safety implications. Scand. J. Work Environ. Heal 2011, 37, 173-185. [CrossRef]

12. Gates, M.; Wingert, A.; Featherstone, R.; Samuels, C.; Simon, C.; Dyson, M.P. Impact of fatigue and insufficient sleep on physician and patient outcomes: A systematic review. BMJ Open 2018, 8, e021967. [CrossRef]

13. Vincent, C. Patient Safety, 2nd ed.; John Wiley \& Sons: West Sussex, UK, 2011.

14. Landrigan, C.P.; Rothschild, J.M.; Cronin, J.W.; Kaushal, R.; Burdick, E.; Katz, J.T.; Lilly, C.M.; Stone, P.H.; Lockley, S.W.; Bates, D.W.; et al. Effect of Reducing Interns' Work Hours on Serious Medical Errors in Intensive Care Units. N. Engl. J. Med. 2004, 351, 1838-1848. [CrossRef]

15. British Medical Association. Fatigue and sleep deprivation-The impact of different working patterns on doctors. 2018. Available online: https://web.archive.org/web/20200810152830/https://www.bma.org.uk/med ia/1074/bma_fatigue-sleep-deprivation-briefing-jan2017.pdf (accessed on 10 August 2020).

16. Mak, N.T.; Li, J.; Wiseman, S.M. Resident Physicians are at Increased Risk for Dangerous Driving after Extended-duration Work Shifts: A Systematic Review. Cureus 2019, 11, e4843. [CrossRef]

17. Barger, L.K.; Cade, B.E.; Ayas, N.T.; Cronin, J.W.; Rosner, B.; Speizer, F.E.; Czeisler, C.A. Extended work shifts and the risk of motor vehicle crashes among interns. N. Engl. J. Med. 2005, 352, 125-134. [CrossRef] 
18. Ayas, N.T.; Barger, L.K.; Cade, B.E.; Hashimoto, D.M.; Rosner, B.; Cronin, J.W.; Speizer, F.E.; Czeisler, C.A. Extended work duration and the risk of self-reported percutaneous injuries in interns. JAMA 2006, 296, 1055-1062. [CrossRef]

19. Bilimoria, K.Y.; Chung, J.W.; Hedges, L.V.; Dahlke, A.R.; Love, R.; Cohen, M.E.; Hoyt, D.B.; Yang, A.D.; Tarpley, J.L.; Mellinger, J.D.; et al. National cluster-randomized trial of duty-hour flexibility in surgical training. N. Engl. J. Med. 2016, 374, 713-727. [CrossRef]

20. Birkmeyer, J.D. Surgical resident duty-hour rules-Weighing the new evidence. N. Engl. J. Med. 2016, 374, 783-784. [CrossRef]

21. World Health Organization. Global strategy on human resources for health: Workforce 2030. 2016. Available online: https://web.archive.org/web/20200810153104/https://apps.who.int/iris/bitstream/handle/10665/250 368/9789241511131-eng.pdf;jsessionid=C02BD48BF949E4BBA7AEE9F1434507D3? sequence=1 (accessed on 10 August 2020).

22. Goldacre, M.J.; Goldacre, R.; Lambert, T.W. Doctors who considered but did not pursue specific clinical specialties as careers: Questionnaire surveys. J. R. Soc. Med. 2012, 105, 166-176. [CrossRef]

23. Sun, N.Z.; Maniatis, T. Scheduling in the context of resident duty hour reform. BMC Med. Educ. 2014, 14, S1. [CrossRef]

24. Reynolds, A.C.; Paterson, J.L.; Ferguson, S.A.; Stanley, D.; Wright, K.P.; Dawson, D. The shift work and health research agenda: Considering changes in gut microbiota as a pathway linking shift work, sleep loss and circadian misalignment, and metabolic disease. Sleep Med. Rev. 2017, 34, 3-9. [CrossRef]

25. Stimpfel, A.W.; Aiken, L.H. Hospital staff nurses' shift length associated with safety and quality of care. J. Nurs. Care Qual. 2013, 28, 122. [CrossRef]

26. Folkard, S.; Tucker, P. Shift work, safety and productivity. Occup Med. 2003, 53, 95-101. [CrossRef]

27. Wang, X.; Ji, A.; Zhu, Y.; Liang, Z.; Wu, J.; Li, S.; Meng, S.; Zheng, X.; Xie, L. A meta-analysis including dose-response relationship between night shift work and the risk of colorectal cancer. Oncotarget 2015, 6, 25046-25060. [CrossRef]

28. Torquati, L.; Mielke, G.I.; Brown, W.J.; Kolbe-Alexander, T. Shift work and the risk of cardiovascular disease. A systematic review and meta-analysis including dose-response relationship. Scand. J. Work Environ. Heal 2018, 44, 229-238. [CrossRef] [PubMed]

29. Kecklund, G.; Axelsson, J. Health consequences of shift work and insufficient sleep. BMJ 2016, 355, i5210. [CrossRef] [PubMed]

30. Levine, A.; Adusumilli, J.; Landrigan, C. Effects of reducing or eliminating resident work shifts over 16 hours: A systematic review. Sleep 2010, 33, 1043-1053. Available online: http://www.pubmedcentral.nih.gov/articler ender.fcgi? artid=2910534\&tool=pmcentrez\&rendertype=abstract (accessed on 13 August 2014).

31. Van Dongen, H.P.A.; Maislin, G.; Mullington, J.M.; Dinges, D.F. The cumulative cost of additional wakefulness: Dose-response effects on neurobehavioral functions and sleep physiology from chronic sleep restriction and total sleep deprivation. Sleep 2003, 26, 117-126. [CrossRef] [PubMed]

32. Republic of South Africa. Determination: Earnings Threshold. Gov Gaz 2014. Available online: https://web.archive.org/web/20200810153532/https:/www.gov.za/sites/default/files/gcis_document/201409/ 37795gon531.pdf (accessed on 10 August 2020).

33. Department of Labour. Code of Good Practice on the Arrangement of Working Time. 1997. Available online: https://web.archive.org/web/20200810153818/http://www.labour.gov.za/DocumentCenter/Code\%20of\%2 0Good \%20Practice/Basic\%20Condition/Code\%20of\%20Good \%20Practice \%20on\%20the \%20Arrangement $\%$ 20of\%20Working\%20Time.PDF (accessed on 10 August 2020).

34. Health Professions Council of South Africa. Handbook on Internship Training; Health Professions Council of South Africa: Pretoria, South Africa, 2013.

35. Safe Working Hours. Share Your Safe Working Hours Story. Youtube. Available online: https://www.youtub e.com/watch?v=lDGwc7UAAmE\&feature=youtu.be (accessed on 12 August 2020).

36. Wahl, F. Township ER Trailer. Youtube. Available online: https://www.youtube.com/watch?v=RuGLeIV6v9g (accessed on 12 August 2020).

37. Health Professions Council of South Africa. Handbook on Internship Training; Health Professions Council of South Africa: Pretoria, South Africa, 2017. 
38. The Safe Working Hours Campaign. The 2017 Limit on Continuous Shifts for South African Junior Doctors. 2019. Available online: https://web.archive.org/web/20200810154144/https://17d779f3-c893-4fa9-a652-42 f3e43cc691.filesusr.com/ugd/068754_8ceab80918ba423abbfc8f23d0c76a46.pdf?index=true (accessed on 10 August 2020).

39. Republic of South Africa. Occupational Health and Safety Act, 1993 (Act no 85 of 1993); Government Gazette: Randburg, South Africa, 1993.

40. Republic of South Africa. National Health Act, 2004 (Act No. 61 of 2003). 2004. Available online: https://web.archive.org/web/20200810154543/https://www.gov.za/sites/default/files/gcis_document/201409/ a61-03.pdf (accessed on 10 August 2020).

41. The National Institute for Occupational Safety and Health (NIOSH). Hierarchy of Controls. Available online: https://web.archive.org/web/20200703112701/https:/www.cdc.gov/niosh/topics/hierarchy/default.html (accessed on 3 July 2020).

42. Pittman, M. NIOSH's 'Hierarchy of Controls'. Wikipedia. Available online: https://commons.wikimedia.org/ wiki/File:NIOSH $\backslash \mathrm{T} 1 \mid$ textquoterights_|T1|textquotedblleftHierarchy_of_Controls_infographic $\backslash \mathrm{T} 1 \backslash$ textquot edblright_as_SVG.svg (accessed on 11 August 2020).

43. Arora, V.; Dunphy, C.; Chang, V.Y.; Ahmad, F.; Humphrey, J.H.; Meltzer, D. The effects of on-duty napping on intern sleep time and fatigue. Ann. Intern. Med. 2006, 144, 792-798. [CrossRef]

44. Tucker, P.; Brown, M.; Dahlgren, A.; Davies, G.; Ebden, P.; Folkard, S.; Hutchings, H.; Åkerstedt, T. The impact of junior doctors' worktime arrangements on their fatigue and well-being. Scand. J. Work Environ. Heal 2010, 36, 458-465. [CrossRef]

45. Michael, E.; Patel, C. Improving medical handover at the weekend: A quality improvement project. BMJ Qual. Improv. Rep. 2015, 4. [CrossRef]

46. McKenna, H.; Wilkes, M. Optimising sleep for night shifts. Br. Med. J. 2018, 360, j5637. [CrossRef]

47. Isaacs, L. Armbands to Show Doctor Fatigue Levels. Independent Online. Available online: https://web.archive.org/web/20200703113016/https://www.iol.co.za/capetimes/news/armbands-to-showdoctor-fatigue-levels-2072590 (accessed on 3 July 2020).

(C) 2020 by the authors. Licensee MDPI, Basel, Switzerland. This article is an open access article distributed under the terms and conditions of the Creative Commons Attribution (CC BY) license (http://creativecommons.org/licenses/by/4.0/). 